\title{
Potencial polinizador para justiça social dos núcleos RIEC FURB e RIEC ECOFOR
}

\author{
Vera Lúcia Simão ${ }^{1}$ \\ https://orcid.org/0000-0001-6169-0242 \\ Vera Lúcia de Souza e Silva ${ }^{2}$ \\ https://orcid.org/0000-0003-0925-6013 \\ Saturnino de la Torre ${ }^{3}$ \\ https://orcid.org/0000-0003-3898-0465
}

\section{Resumo}

A educação ocupa um lugar importante na formação humana por promover um descortinar da cegueira do conhecimento. Para tanto, a educaçáo requer espaços que promovam a construçáo do saber, religue conceitos de igualdade e sociedade a fim de possibilitar o ato de educar em toda sua inteireza. Com o objetivo de relatar as principais atividades que nortearam a atuação dos Núcleos RIEC FURB e RIEC ECOFOR em Santa Catarina, engajados com a justiça social, este artigo foi elaborado a partir de uma pesquisa documental e bibliográfica, com base de dados nos registros dos núcleos e publicaçóes relacionadas. Os dados demonstram uma intensa atividade de ambos os núcleos no desenvolvimento de ensino, pesquisa e extensão e revelam a potencialidade socializadora das açóes empreendidas na direção de consolidar o desempenho da Rede Internacional de Escolas Criativas desde a educação básica até o ensino superior no período de 2012 a 2020.

Palavras-chave: Justiça social, Ecoformação, Escolas criativas, Formação de professores, RIEC.

\footnotetext{
${ }^{1}$ Doutora em Educação e Sociedade (UB). Professora no Programa de Mestrado Profissional em Educaçāo Básica (PPGEB UNIARP) e Professora Visitante no Programa de Pós-Graduação em Ensino de Ciências Naturais e Matemática (PPGECIM FURB). Membro da Rede Internacional de Escolas Criativas - RIEC; RIEC FURB; RIEC UNIARP; RIEC ECOFOR. E-mail: vsimao2@gmail.com.

2 Doutora em Engenharia de Produçáo (UFSC). Professora aposentada da FURB. Ex-Professora no Programa de Pós-Graduaçáo em Ensino de Ciências Naturais e Matemática (PPGECIM FURB). Secretária Geral da Rede Internacional de Escolas Criativas (RIEC), com sede em Barcelona, e Coordenadora do Núcleo RIEC ECOFOR, Santa Catarina. Membro da Rede Internacional de Escolas Criativas - RIEC; RIEC FURB; RIEC ECOFOR. E-mail: veraluciabalneario@gmail.com.

3 Professor Doutor, Emérito, Coordenador do programa de doutorado e do Grupo de Investigaçáo e Assessoramento Didático (GIAD) da Universidade de Barcelona e Criador e Coordenador Geral da Rede Internacional de Escolas Criativas (RIEC). E-mail: sentipensar@yahoo.es.
} 


\section{Pollinating potential of the RIEC FURB and RIEC ECOFOR centers}

\section{Abstract}

Education occupies an important place in human formation as it promotes the unveiling of knowledge blindness. For that, education requires spaces that promote the construction of knowledge, reconnect concepts of equality and society in order to enable the act of educating in all its entirety. In order to report the main activities that guided the activities of the RIEC FURB and RIEC ECOFOR Centers in Santa Catarina, engaged with social justice, this article was prepared based on a documentary and bibliographic research, from data in the records of the centers and related publications. The data demonstrate an intense activity of both centers in the development of teaching, research and extension and reveal the socializing potential of the actions undertaken in order to consolidate the performance of the International Network of Creative Schools from basic education to higher education in the period from 2012 to 2020 . Keywords: Social justice, Ecoformation, Creative schools, Teacher training, RIEC.

\section{Preparando o terreno para a semeadura}

No ano de 2005, Saturnino de la Torre, criador e coordenador geral da Rede Internacional de Escolas Criativas (RIEC), iniciou contato com a Universidade Regional de Blumenau (FURB). Dessa aproximação, surgiu uma parceria que se mostrou conveniente e muito producente, o que levou a uma ampliação das parcerias. Naquela época, alguns cursos estavam desenvolvendo projetos interdisciplinares tais como Administração, Matemática, Letras Português/Inglês, Contabilidade, entre outros. Nesse tempo, o Grupo de Investigação e Assessoramento Didático (GIAD) da Universidade de Barcelona (UB) estava realizando pesquisas na abordagem do pensamento complexo e o olhar transdisciplinar.

O professor S. de la Torre acompanhou a proposta dos projetos interdisciplinares nos anos posteriores, evidenciando sua consolidação na abordagem transdisciplinar, com a participação da professora Maria José Carvalho de Souza Domingues, que naquele período ocupava o cargo de PróReitora de Ensino Médio, Graduação e Profissionalizante da FURB, partilhando a experiência dos projetos no I Congresso Internacional de Innovación Docente: Transdisciplinariedad y Ecoformación, celebrado em Barcelona no ano de 2007. Por meio da professora M. J. Domingues, o professor S. de la Torre participou por diversas vezes de eventos na FURB para alunos de graduaçáo e mestrado no período de 2005 a 2010. Essa colaboração concretizou-se, para além de palestras sobre criatividade e participação em 
Fóruns de Barcelona, na publicação do artigo "Estilos de vida e aprendizagem universitária” de S. de la Torre e J. Tejada na publicação coordenada por M. J. Domingues e A. Silva com o título "Gestão de Ensino superior" (2008, p. 63-86).

Com o objetivo de relatar as principais atividades que nortearam a atuação dos Núcleos RIEC FURB e RIEC ECOFOR em Santa Catarina, engajados com a justiça social, este artigo foi elaborado a partir de uma pesquisa documental e bibliográfica, com base de dados nos registros dos núcleos e publicaçóes relacionadas.

Esta é uma amostra de como foram preparados o terreno e o ambiente necessários para avançar em 2012 para a próxima fase de semeadura e fertilização da Rede Internacional de Escolas Criativas na FURB.

\section{A semeadura e constituição do núcleo RIEC FURB}

Pode-se dizer que o IV Fórum sobre Inovação e Criatividade, organizado pelo grupo GIAD em Barcelona (junho/2012), dedicado à Adversidade e Escolas Criativas, é considerado o germe da semente que lançou suas raízes no Brasil, pois foi nesse Fórum que a Red Internacional de Escuelas Creativas (RIEC) foi criada na Universidade de Barcelona. A FURB esteve representada no Fórum e na criação da RIEC com a apresentação de pesquisas relativas à educação transdisciplinar e criativa, por meio da participação da professora Vera Lúcia de Souza e Silva.

Em 20 de julho de 2012, a Universidade Regional de Blumenau firmou Acordo de Adesão com a RIEC, dando início ao Programa de Extensão Rede de Escolas Criativas da FURB (RIEC FURB) que, conforme Silva e Torre (2014, p. 33), baseava-se "[...] na interdisciplinaridade, transdisciplinaridade, complexidade e na ecoformação como princípios investigativos e formativos." A professora Vera Lúcia de Souza e Silva foi quem constituiu o Núcleo RIEC FURB, aproveitando a participação do professor S. de la Torre, que sempre o considerou inspirador.

A RIEC pauta-se na pesquisa em rede de conhecimentos e experiências com base científica, fruto da prática pedagógica com evidências em diversos espaços escolares. A RIEC FURB atua na formação inicial e continuada de professores nos campos do ensino, pesquisa e extensão e está conveniada à RIEC, atuante em nove países da Europa e América Latina. Apresenta 
atualmente mais de 15 núcleos no Brasil, sendo praticamente eles todos vinculados a Instituições de Ensino Superior (IES). Está aberta a novas pessoas, grupos e instituiçóes comprometidas com uma visão de educação para a cultura de paz, baseada na justiça social, no desenvolvimento humano, no trabalho de cooperação criativo e planetário. Aborda desafios para se pensar a educação escolar na contemporaneidade a partir da realidade local religando à realidade global.

A RIEC apresenta três objetivos principais: "1) Criar uma consciência coletiva de mudança; 2) Gerar ações transformadoras; 3) Promover ações investigadoras e polinizadoras." (RIEC, 2017, p. 1, tradução nossa).

Primeiro, procura criar uma Consciência Coletiva na educação a partir de instituiçóes, criativas e inovadoras, para promover uma educação transformadora baseada em valores humanos, justiça social e habilidades para a vida. Além de estabelecer um diálogo constante entre saberes inter e transdisciplinares, experiências docentes, gestão administrativa e pedagógica. No livro intitulado "Os sete saberes necessários à educação do futuro", do autor Morin (2011), damos especial destaque para "As cegueiras do conhecimento: o erro e a ilusão" (MORIN, 2011, p. 19), visto sua relação com a justiça social quanto ao erro e à ilusão. Segundo Morin (2011), o erro e a ilusão paralisam a mente humana e sugere que a educação deva mostrar que não existe conhecimento que náo esteja ameaçado por essas duas condiçóes. Dessa forma, a RIEC ajuda a criar uma consciência coletiva na educação e aplica-se "[...] à identificação da origem de erros, ilusões e cegueiras." (MORIN, 2011, p. 21), por dedicar-se a um trabalho em rede, que se articula para ações de integração de saberes e pessoas.

Segundo, pretende resgatar, reconhecer e difundir (polinizar) o potencial criativo de escolas e instituiçóes educativas com trajetória inovadora, que possam servir de referência e inspiração a outras escolas e ao poder público para a realização de avanços e melhorias no sistema educativo e na promoção da justiça social. Resgatar, reconhecer e difundir são açóes que orientam os processos e promovem avanços educativos como forma de polinizar saberes e oportunidades e, assim, favorecer a justiça social. Muitas escolas possuem um potencial criativo muito grande, que pode ser revelado e ampliado a partir de um trabalho coletivo. Ao criar oportunidades de trabalho em rede, como a RIEC faz, as instituiçóes se reconhecem e se fortalecem, emergindo um empoderamento proveniente das suas próprias açóes educativas. 
Terceiro, promover a pesquisa em nível de graduação e pós-graduação (Mestrado, Doutorado e Pós-Doutorado) e a criação de recursos e instrumentos padronizados que permitam avaliar e reconhecer as instituiçôes que possam servir de referência para as demais. Saber mais sobre os processos de transformação das instituições, suas dificuldades, desigualdades sociais e forma de superá-las. Reconhecer e valorizar a realidade, os anseios, consternaçóes e os problemas como oportunidade de formação e transformação. Quanto às desigualdades sociais, não se pretende que sejamos iguais. A intenção é que as pessoas tenham os direitos básicos assegurados, tais como acesso e permanência à educação de qualidade. Investir em pesquisas que venham a contribuir para a melhoria da qualidade da formação inicial e continuada de professores com o propósito de uma educação transformadora, ecoformadora, sustentável, planetária e democrática são possibilidades com vistas à promoção de justiça social.

A Rede Internacional de Escolas Criativas: Construindo a Escola do Século XXI - RIEC, tem por objetivo investigar escolas criativas e contribuir para o reconhecimento e a socialização de projetos e processos institucionais, construídos coletivamente, e que sejam criativos, transformadores, fruto de uma nova consciência e que seja nutrida por uma cultura de mudança, uma cultura transformadora. Assim sendo, almeja-se "criar redes de escolas e instituiçóes que possam intercambiar entre si”. (TORRE, 2012, p. 11-12, grifo do autor, tradução nossa).

No período de 2012 a 2015, a RIEC FURB promoveu encontros mensais, que aconteciam no Laboratório de Instrumentação para o Ensino (LIE). Nos encontros, participavam professores da educação básica e graduação, gestores, acadêmicos, mestrandos e profissionais das mais variadas áreas do saber, demonstrando interesse e curiosidade na proposta da RIEC, com o intuito de trocar experiências e firmar parcerias. Os encontros objetivavam "[...] auxiliar profissionais da educação em busca de práticas educativas que contemplem os avanços das ciências e das tecnologias, bem como as demandas pessoais, sociais e ambientais deste início de século." (SILVA; TORRE, 2014, p. 33).

Como professora do Programa de Pós-Graduação em Ensino de Ciências Naturais e Matemática (PPGECIM) - FURB -, V. L. de Souza e 
Silva formou um grupo com cerca de 50 participantes composto por professores da educação básica ao ensino superior, pesquisadores, estudantes de graduação e pós-graduação que se reuniam periodicamente para o planejamento e a realização de projetos criativos com base de implementação nas escolas de educação básica da região. Obteve recursos e autorizaçôes da Coordenação de Aperfeiçoamento de Pessoal de Nível Superior (CAPES) para implementação e publicação dos resultados desses projetos. Um dos projetos culminou com a vinda em 2014 para o mestrado do PPGECIM - FURB -, na condição de professor visitante, do professor Saturnino de la Torre, coordenador geral da RIEC e professor emérito da Universidade de Barcelona. Sua presença contribuiu para fortalecer a colaboração conjunta em Projetos de Pesquisa, Encontros e publicaçóes entre o grupo GIAD e a FURB, o que se mostrou conveniente pela ampliação da colaboração em pesquisa, formação e avaliação de processos educativos criativos desde a educação básica até o ensino superior.

Nesse viés, essas ações da RIEC FURB consolidaram o segundo objetivo da RIEC no que se refere a reconhecer e difundir (polinizar) o potencial criativo de escolas e instituiçóes educativas com trajetória inovadora na regiáo do Vale do Itajaí.

Em relação às Escolas Criativas, Torre (2013, p. 13) define que:

[...] vão mais adiante do lugar a qual partem (transcendem), que dão mais o que tem e ultrapassam o que delas se espera (recriam), que reconhecem o melhor de seus estudantes e professores (valorizam), que crescem por dentro e por fora, buscando em tudo a qualidade e a melhora (transformam).

Dessa forma, cabe a cada instituição organizar uma proposta curricular contextualizada, valorizando a história de vida dos estudantes, dos professores e suas particularidades, bem como questóes de justiça social. Escolas Criativas são, portanto, aquelas que transcendem a sua condição de origem, recriam ao ultrapassar o que delas se espera, valorizam ao reconhecer potenciais e transformam enquanto são também transformadas (TORRE, 2009). 


\section{Desenvolvimento e polinizaçáo}

A presença da RIEC na FURB denota um leque de possibilidades de cunho de justiça social, pedagógico, cultural, tecnológico, bem como científico, fortalecendo os pilares da Universidade nas dimensôes de ensino, pesquisa e extensão. Possibilidades que podem ser evidenciadas no desenvolvimento de pesquisas em Formação de Professores: Ecoformação, Criatividade e Transdisciplinaridade, vinculadas tanto ao PPGECIM como aos cursos de Licenciatura da FURB, especialmente em pesquisas para Trabalhos de Conclusão de Curso (TCCs), dissertaçóes de mestrado e teses de doutorado.

Diante da necessidade de consolidar e oficializar as açóes da RIEC em apoio a processos educativos criativos e ecoformadores no litoral de Santa Catarina, em julho de 2018, foi criado o Núcleo RIEC ECOFOR. Com 17 participantes, sob a coordenação das professoras Vera L. S. e Silva e Vera L. Simão, a fundação do Núcleo foi apoiada pelos professores da RIEC: Maria Antónia Pujol e Saturnino de la Torre, da Universidade de Barcelona, que se efetivaram membros fundadores da RIEC ECOFOR. No dia da fundação da RIEC ECOFOR, uma mensagem de Saturnino de la Torre aos membros do Núcleo enfatizava que:

La labor que estáis realizando es encomiable haciendo visible el gran potencial de RIEC. El Núcleo ECOFOR se ha convertido en un referente internacional de Ecoformación y de la metodología de investigación-acción transformadora para pesquisar en los procesos de cambio y mejora de la educación con apoyo en la Creatividad. (TORRE, 2018, p. 1).

Dessa forma, com açôes voltadas à (Eco)formação de Professores desde a educação básica até o ensino superior, além de pesquisas relacionadas, a RIEC ECOFOR baseada nos princípios da Ecoformação, Transdisciplinaridade e Criatividade estende suas açôes aos municípios catarinenses de Brusque, Balneário Camboriú, Gaspar, Indaial, Itajaí, Massaranduba e Blumenau, com o propósito de ampliar as implementaçóes de projetos de reconhecimento e apoio a escolas criativas. As reunióes bimestrais acontecem em locais distintos e com o objetivo de aproximar os membros das escolas aos estudos e formaçóes coletivas, que se traduzem em 
momentos de trocas e polinização de saberes teóricos e práticos, com abordagens teórica e metodológica baseadas nos princípios e metas da RIEC. Para melhor destaque, apresentamos no Quadro a seguir um compilado de ações proeminentes dos Núcleos RIEC FURB e RIEC ECOFOR, que juntos colaboram para a evolução da educação, fundamentados nos princípios da transdisciplinaridade e ecoformação, além de serem permeados por um trabalho com valores essenciais para a convivência, como a solidariedade e a cooperação; o que pode contribuir para a justiça social. Ressaltamos que, para não ultrapassar os limites de extensão deste trabalho, não serão citados os artigos publicados e participaçóes em eventos nacionais e internacionais. Esses dados são facilmente encontrados no Curriculum Lattes dos autores.

Quadro 1: Evidências de pesquisas e açóes proeminentes dos Núcleos RIEC FURB e RIEC ECOFOR

\begin{tabular}{|c|c|c|c|c|c|}
\hline Título & Ano & Pesquisador & Tipo & $\begin{array}{l}\text { Local / } \\
\text { Instituiçáo }\end{array}$ & $\begin{array}{l}\text { Núcleo } \\
\text { RIEC }\end{array}$ \\
\hline $\begin{array}{l}\text { Clubes de Ciências como espaço } \\
\text { de alfabetizaçáo científica e } \\
\text { ecoformaçāo } \\
\text { (Revista Atos de Pesquisa em } \\
\text { Educaçáo) }\end{array}$ & 2012 & $\begin{array}{l}\text { Edson } \\
\text { Schroeder e Celso } \\
\text { Menezes }\end{array}$ & Artigo & PPGE FURB & $\begin{array}{l}\text { RIEC } \\
\text { FURB }\end{array}$ \\
\hline $\begin{array}{l}\text { Investigaçáo sobre Criatividade } \\
\text { em uma Escola da Rede Pública } \\
\text { de Blumenau - SC }\end{array}$ & 2013 & $\begin{array}{l}\text { Daiana Cardoso } \\
\text { Orientadora: } \\
\text { Vera Lúcia de Souza } \\
\text { e Silva }\end{array}$ & TCC & $\begin{array}{l}\text { Curso de } \\
\text { Pedagogia } \\
\text { FURB }\end{array}$ & $\begin{array}{l}\text { RIEC } \\
\text { FURB }\end{array}$ \\
\hline $\begin{array}{l}\text { Certificaçáo de Escola Criativa } \\
\text { pela RIEC FURB à Escola } \\
\text { Básica Municipal (EBM) } \\
\text { Visconde de Taunay, pelo } \\
\text { Coordenador Geral da RIEC } \\
\text { Saturnino de la Torre, da } \\
\text { Universidade de Barcelona. }\end{array}$ & 2013 & $\begin{array}{l}\text { Saturnino de la } \\
\text { Torre e Vera L. S. } \\
\text { Silva }\end{array}$ & $\begin{array}{l}\text { Certificaçã } \\
\text { o }\end{array}$ & $\begin{array}{l}\text { PPGECIM } \\
\text { FURB }\end{array}$ & $\begin{array}{l}\text { RIEC } \\
\text { FURB }\end{array}$ \\
\hline $\begin{array}{l}\text { Inovando na sala de aula: } \\
\text { instituiçóes transformadoras } \\
\text { (Nova Letra) }\end{array}$ & 2013 & $\begin{array}{l}\text { Saturnino de la } \\
\text { Torre, Maria } \\
\text { Antónia Pujol e Vera } \\
\text { Lúcia de S. e Silva } \\
\text { (Org.) }\end{array}$ & $\begin{array}{l}\text { Publicaçáo } \\
\text { de Livro }\end{array}$ & $\begin{array}{l}\text { PPGECIM } \\
\text { FURB }\end{array}$ & $\begin{array}{l}\text { RIEC } \\
\text { FURB }\end{array}$ \\
\hline $\begin{array}{l}\text { Visita de estudos ao Grupo } \\
\text { GIAD - da Universidade } \\
\text { de Barcelona (UB) e RIEC - } \\
\text { Rede Internacional de Escolas } \\
\text { Criativas (convênio UB e } \\
\text { FURB) }\end{array}$ & $\begin{array}{l}2013 \\
\text { e } \\
2014\end{array}$ & $\begin{array}{l}\text { Vera Lúcia de Souza } \\
\text { e Silva }\end{array}$ & $\begin{array}{l}\text { Intercâmbi } \\
\text { os } \\
\text { Acadêmico } \\
\mathrm{s}\end{array}$ & $\begin{array}{l}\text { PPGECIM } \\
\text { FURB }\end{array}$ & $\begin{array}{l}\text { RIEC } \\
\text { FURB }\end{array}$ \\
\hline $\begin{array}{l}\text { Estágio curricular } \\
\text { supervisionado curso de } \\
\text { Ciências Biológicas }\end{array}$ & 2014 & $\begin{array}{l}\text { Vera Lúcia de Souza } \\
\text { e Silva }\end{array}$ & $\begin{array}{l}\text { Estágio na } \\
\text { Licenciatur } \\
\text { a }\end{array}$ & $\begin{array}{l}\text { Estágio na } \\
\text { EBM } \\
\text { Visconde de } \\
\text { Taunay, de }\end{array}$ & $\begin{array}{l}\text { RIEC } \\
\text { FURB }\end{array}$ \\
\hline
\end{tabular}




\begin{tabular}{|c|c|c|c|c|c|}
\hline & & & & $\begin{array}{l}\text { Blumenau- } \\
\text { SC }\end{array}$ & \\
\hline $\begin{array}{l}\text { Ecoformação de professores da } \\
\text { educaçáo básica no programa } \\
\text { novos talentos da CAPES }\end{array}$ & 2014 & $\begin{array}{l}\text { Fabiana Fachini } \\
\text { Orientador: Mauro } \\
\text { Scharf. } \\
\text { Coorientadora: Vera } \\
\text { Lúcia de Souza e } \\
\text { Silva. } \\
\text { Presença na Banca } \\
\text { do Prof. Dr. } \\
\text { Saturnino de la } \\
\text { Torre }\end{array}$ & Dissertaçáo & $\begin{array}{l}\text { PPGECIM } \\
\text { FURB }\end{array}$ & $\begin{array}{l}\text { RIEC } \\
\text { FURB }\end{array}$ \\
\hline $\begin{array}{l}\text { Investigaçáo sobre a formaçáo } \\
\text { continuada de professores na } \\
\text { Rede Internacional de Escolas } \\
\text { Criativas }\end{array}$ & 2014 & $\begin{array}{l}\text { Neusa Francisca do } \\
\text { Carmo } \\
\text { Orientadora: } \\
\text { Vera Lúcia de Souza } \\
\text { e Silva }\end{array}$ & TCC & $\begin{array}{l}\text { Curso de } \\
\text { Pedagogia } \\
\text { FURB }\end{array}$ & $\begin{array}{l}\text { RIEC } \\
\text { FURB }\end{array}$ \\
\hline $\begin{array}{l}\text { Desenvolvimento do processo } \\
\text { de ecoformaçáo e criatividade de } \\
\text { uma turma de anos iniciais de } \\
\text { uma instituiçáo de ensino de } \\
\text { educaçáo básica na regiáo de } \\
\text { Blumenau - SC }\end{array}$ & 2014 & $\begin{array}{l}\text { Regiane de Souza } \\
\text { Orientadora: } \\
\text { Vera Lúcia de Souza } \\
\text { e Silva }\end{array}$ & TCC & $\begin{array}{l}\text { Curso de } \\
\text { Pedagogia } \\
\text { FURB }\end{array}$ & $\begin{array}{l}\text { RIEC } \\
\text { FURB }\end{array}$ \\
\hline $\begin{array}{l}\text { Escola sustentável: concepçóes } \\
\text { de uma comunidade escolar de } \\
\text { educaçáo básica da rede pública } \\
\text { municipal de Blumenau }\end{array}$ & 2014 & $\begin{array}{l}\text { Silvia Buzana } \\
\text { Orientadora: } \\
\text { Vera Lúcia de Souza } \\
\text { e Silva }\end{array}$ & TCC & $\begin{array}{l}\text { Curso de } \\
\text { Pedagogia } \\
\text { FURB }\end{array}$ & $\begin{array}{l}\text { RIEC } \\
\text { FURB }\end{array}$ \\
\hline $\begin{array}{l}\text { Novos Talentos: processos } \\
\text { educativos em ecoformação } \\
\text { (Nova Letra) }\end{array}$ & 2014 & $\begin{array}{l}\text { Edson Schroeder e } \\
\text { Vera L. de S. e Silva } \\
\text { (Org.) }\end{array}$ & $\begin{array}{l}\text { Publicaçáo } \\
\text { de Livro }\end{array}$ & $\begin{array}{l}\text { PPGECIM } \\
\text { FURB }\end{array}$ & $\begin{array}{l}\text { RIEC } \\
\text { FURB }\end{array}$ \\
\hline $\begin{array}{l}\text { Novos Talentos: processos } \\
\text { educativos com projetos } \\
\text { criativos ecoformadores } \\
\text { (Nova Letra) }\end{array}$ & 2015 & $\begin{array}{l}\text { Schirley } \\
\text { Pasquali, Vera L. de } \\
\text { S. e Silva (Org.) }\end{array}$ & $\begin{array}{l}\text { Publicaçáo } \\
\text { de Livro }\end{array}$ & $\begin{array}{l}\text { PPGECIM } \\
\text { FURB }\end{array}$ & $\begin{array}{l}\text { RIEC } \\
\text { FURB }\end{array}$ \\
\hline $\begin{array}{l}\text { Dimensóes da etnomatemática } \\
\text { aplicadas no processo de ensino } \\
\text { de eletricidade no curso } \\
\text { profissionalizante }\end{array}$ & 2015 & $\begin{array}{l}\text { Lourenço Gabriel } \\
\text { Isolani } \\
\text { Orientadora: } \\
\text { Vera Lúcia de Souza } \\
\text { e Silva } \\
\end{array}$ & Dissertaçáo & $\begin{array}{l}\text { PPGECIM } \\
\text { FURB }\end{array}$ & $\begin{array}{l}\text { RIEC } \\
\text { FURB }\end{array}$ \\
\hline $\begin{array}{l}\text { As contribuiçóes do Laboratório } \\
\text { de educaçáo matemática Isaac } \\
\text { Newton para o ensino de } \\
\text { matemática na educaçáo básica } \\
\text { na perspectiva da } \\
\text { etnomatemática }\end{array}$ & 2015 & $\begin{array}{l}\text { Cristiano Rodolfo } \\
\text { Tironi } \\
\text { Orientadora: } \\
\text { Vera Lúcia de Souza } \\
\text { e Silva } \\
\end{array}$ & Dissertaçáo & $\begin{array}{l}\text { PPGECIM } \\
\text { FURB }\end{array}$ & $\begin{array}{l}\text { RIEC } \\
\text { FURB }\end{array}$ \\
\hline $\begin{array}{l}\text { Projetos criativos } \\
\text { ecoformadores: uma proposta de }\end{array}$ & 2015 & $\begin{array}{l}\text { Schirley Pasquali } \\
\text { Orientadora: }\end{array}$ & Dissertaçáo & $\begin{array}{l}\text { PPGECIM } \\
\text { FURB }\end{array}$ & $\begin{array}{l}\text { RIEC } \\
\text { FURB }\end{array}$ \\
\hline
\end{tabular}




\begin{tabular}{|c|c|c|c|c|c|}
\hline $\begin{array}{l}\text { ensino de ciências para o estudo } \\
\text { da alimentaçấo saudável }\end{array}$ & & $\begin{array}{l}\text { Vera Lúcia de Souza } \\
\text { e Silva } \\
\text { Presença na Banca } \\
\text { do Prof. Dr. } \\
\text { Saturnino de la } \\
\text { Torre }\end{array}$ & & & \\
\hline $\begin{array}{l}\text { Projetos Criativos na Prática } \\
\text { Pedagógica: cantar e encantar a } \\
\text { aprendizagem }\end{array}$ & 2015 & $\begin{array}{l}\text { Maria J. de Pinho, } \\
\text { Marilza V. R. } \\
\text { Suanno e Joāo } \\
\text { Henrique Suanno } \\
\text { (Org.) }\end{array}$ & $\begin{array}{l}\text { Capítulo } \\
\text { nessa Obra }\end{array}$ & UFT e UFG & $\begin{array}{l}\text { RIEC } \\
\text { FURB }\end{array}$ \\
\hline $\begin{array}{l}\text { Contribuiçóes da } \\
\text { etnomatemática ao ensino de } \\
\text { matemática para a educaçáo de } \\
\text { jovens e adultos a partir de } \\
\text { práticas cotidianas da } \\
\text { construçáa civil }\end{array}$ & 2016 & $\begin{array}{l}\text { Marcelo Azevedo de } \\
\text { Souza } \\
\text { Orientadora: } \\
\text { Vera Lúcia de Souza } \\
\text { e Silva }\end{array}$ & Dissertaçáo & $\begin{array}{l}\text { PPGECIM } \\
\text { FURB }\end{array}$ & $\begin{array}{l}\text { RIEC } \\
\text { FURB }\end{array}$ \\
\hline $\begin{array}{l}\text { Relaçóes entre ambientes } \\
\text { educativos e suas contribuiçóes } \\
\text { para o desenvolvimento de } \\
\text { experiências criativas } \\
\text { na educaçáo infantil } \\
\end{array}$ & 2016 & $\begin{array}{l}\text { Sara Amanda Ronchi } \\
\text { Orientadora: } \\
\text { Vera Lúcia Simāo }\end{array}$ & TCC & $\begin{array}{l}\text { Curso de } \\
\text { Pedagogia } \\
\text { FURB }\end{array}$ & $\begin{array}{l}\text { RIEC } \\
\text { FURB }\end{array}$ \\
\hline $\begin{array}{l}\text { (Eco)Formaçáo de professores } \\
\text { na educaçáo básica: uma } \\
\text { experiência a partir de projetos } \\
\text { criativos ecoformadores }\end{array}$ & 2017 & $\begin{array}{l}\text { Jeane Pitz Pukall } \\
\text { Orientadora: Arleide } \\
\text { Rosa da Silva } \\
\text { Coorientadora: Vera } \\
\text { Lúcia de Souza e } \\
\text { Silva }\end{array}$ & Dissertaçáo & $\begin{array}{l}\text { PPGECIM } \\
\text { FURB }\end{array}$ & $\begin{array}{l}\text { RIEC } \\
\text { FURB }\end{array}$ \\
\hline $\begin{array}{l}\text { Projetos criativos } \\
\text { ecoformadores: contribuiçóes } \\
\text { para o processo de alfabetizaçăo } \\
\text { no } 1^{\circ} \text { ano do ensino } \\
\text { fundamental }\end{array}$ & 2017 & $\begin{array}{l}\text { Eliane de Fátima } \\
\text { Prim Santos } \\
\text { Orientadora: Arleide } \\
\text { Rosa da Silva }\end{array}$ & Dissertaçáo & $\begin{array}{l}\text { PPGECIM } \\
\text { FURB }\end{array}$ & $\begin{array}{l}\text { RIEC } \\
\text { FURB }\end{array}$ \\
\hline $\begin{array}{l}\text { Evidências de desenvolvimento } \\
\text { da autonomia e criatividade } \\
\text { na Educaçáo Infantil a partir } \\
\text { dos registros de experiências } \\
\text { das crianças }\end{array}$ & 2017 & $\begin{array}{l}\text { Júlia Cristina Pedro } \\
\text { Orientadora: } \\
\text { Vera Lúcia Simāo }\end{array}$ & TCC & $\begin{array}{l}\text { Curso de } \\
\text { Pedagogia } \\
\text { FURB }\end{array}$ & $\begin{array}{l}\text { RIEC } \\
\text { FURB }\end{array}$ \\
\hline $\begin{array}{l}\text { Contribuiçóes do ambiente } \\
\text { educativo na organizaçáo das } \\
\text { brincadeiras para o } \\
\text { desenvolvimento da criatividade } \\
\text { na Educaçáo infantil }\end{array}$ & 2017 & $\begin{array}{l}\text { Thaís Tafner } \\
\text { Orientadora: } \\
\text { Vera Lúcia Simáo }\end{array}$ & TCC & $\begin{array}{l}\text { Curso de } \\
\text { Pedagogia } \\
\text { FURB }\end{array}$ & $\begin{array}{l}\text { RIEC } \\
\text { FURB }\end{array}$ \\
\hline $\begin{array}{l}\text { Do jardim de casa para o jardim } \\
\text { de infância: a organizaçâo dos } \\
\text { espaços externos na perspectiva } \\
\text { da ecoformaçáo e criatividade }\end{array}$ & 2018 & $\begin{array}{l}\text { Andressa Daiane } \\
\text { Hein } \\
\text { Orientadora: Vera } \\
\text { Lúcia Simão } \\
\end{array}$ & TCC & $\begin{array}{l}\text { Curso de } \\
\text { Pedagogia } \\
\text { FURB }\end{array}$ & $\begin{array}{l}\text { RIEC } \\
\text { FURB e } \\
\text { RIEC } \\
\text { ECOFO } \\
\text { R } \\
\end{array}$ \\
\hline $\begin{array}{l}\text { Tecendo memórias na prática } \\
\text { do registro no cotidiano da }\end{array}$ & 2018 & $\begin{array}{l}\text { Cibele Cristine } \\
\text { Hausmann }\end{array}$ & TCC & $\begin{array}{l}\text { Curso de } \\
\text { Pedagogia } \\
\text { FURB }\end{array}$ & $\begin{array}{l}\text { RIEC } \\
\text { FURB e } \\
\text { RIEC }\end{array}$ \\
\hline
\end{tabular}




\begin{tabular}{|c|c|c|c|c|c|}
\hline $\begin{array}{l}\text { educaçáo infantil: do olhar } \\
\text { sensível à escuta atenta }\end{array}$ & & $\begin{array}{l}\text { Orientadora: Vera } \\
\text { Lúcia Simáo }\end{array}$ & & & $\begin{array}{l}\text { ECOFO } \\
\mathrm{R}\end{array}$ \\
\hline $\begin{array}{l}\text { Certificaçáo de Professora } \\
\text { Criativa pelas mãos do Prof. Dr. } \\
\text { Saturnino de la Torre }\end{array}$ & 2018 & Jeane Pitz Pukall & $\begin{array}{l}\text { Certificaçá } \\
\text { o }\end{array}$ & $\begin{array}{l}\text { II Seminário } \\
\text { Internacional } \\
\text { de } \\
\text { Ecoformaçáo } \\
- \\
\text { Massarandub } \\
\text { a (SC) }\end{array}$ & $\begin{array}{l}\text { RIEC } \\
\text { ECOFO } \\
\mathrm{R}\end{array}$ \\
\hline $\begin{array}{l}\text { O protagonismo infantil e a } \\
\text { criatividade a partir das } \\
\text { vivências das crianças pequenas }\end{array}$ & 2019 & $\begin{array}{l}\text { Ana Carolyne } \\
\text { Alsleben e } \\
\text { Beatriz Mirella } \\
\text { Malinski Raimundi } \\
\text { Orientadora: Vera } \\
\text { Lúcia Simáo }\end{array}$ & TCC & $\begin{array}{l}\text { Curso de } \\
\text { Pedagogia } \\
\text { FURB }\end{array}$ & $\begin{array}{l}\text { RIEC } \\
\text { FURB e } \\
\text { RIEC } \\
\text { ECOFO } \\
\text { R }\end{array}$ \\
\hline $\begin{array}{l}\text { (AUTO)BIOGRAFIA: } \\
\text { contribuiçóes da autonomia e da } \\
\text { criatividade para uma estudante } \\
\text { surda no curso de pedagogia }\end{array}$ & 2019 & $\begin{array}{l}\text { Camila Pureza } \\
\text { Zanotto } \\
\text { Orientadora: Vera } \\
\text { Lúcia Simáo }\end{array}$ & TCC & $\begin{array}{l}\text { Curso de } \\
\text { Pedagogia } \\
\text { FURB }\end{array}$ & $\begin{array}{l}\text { RIEC } \\
\text { FURB e } \\
\text { RIEC } \\
\text { ECOFO } \\
\text { R }\end{array}$ \\
\hline $\begin{array}{l}\text { As tecnologias da informaçáo e } \\
\text { da comunicaçáo para o } \\
\text { desenvolvimento da autonomia } \\
\text { e da criatividade }\end{array}$ & 2019 & $\begin{array}{l}\text { Aniele Raquel } \\
\text { Steinke } \\
\text { Orientadora: Vera } \\
\text { Lúcia Simáo } \\
\end{array}$ & TCC & $\begin{array}{l}\text { Curso de } \\
\text { Pedagogia } \\
\text { FURB }\end{array}$ & $\begin{array}{l}\text { RIEC } \\
\text { FURB e } \\
\text { RIEC } \\
\text { ECOFO } \\
\text { R }\end{array}$ \\
\hline $\begin{array}{l}\text { A ecoformaçáo continuada de } \\
\text { professoras: religando saberes e } \\
\text { sentidos num Centro de } \\
\text { Educaçáo Infantil }\end{array}$ & 2019 & $\begin{array}{l}\text { Tauana Patrícia } \\
\text { Bonsenhor } \\
\text { Orientadora: Arleide } \\
\text { Rosa da Silva }\end{array}$ & Dissertaçáo & $\begin{array}{l}\text { PPGECIM } \\
\text { FURB }\end{array}$ & $\begin{array}{l}\text { RIEC } \\
\text { FURB }\end{array}$ \\
\hline $\begin{array}{l}\text { Programa de Ecoformaçáo } \\
\text { Continuada de Docentes e } \\
\text { Gestores em Escolas Criativas } \\
\text { do Instituto Crescer }\end{array}$ & $\begin{array}{l}2016 / \\
2019\end{array}$ & $\begin{array}{l}\text { Membros RIEC } \\
\text { ECOFOR }\end{array}$ & $\begin{array}{l}\text { (Eco) } \\
\text { Formaçáo } \\
\text { de } \\
\text { Professores }\end{array}$ & $\begin{array}{l}\text { Instituto } \\
\text { CRESCER - } \\
\text { Itajaí (SC) }\end{array}$ & $\begin{array}{l}\text { RIEC } \\
\text { ECOFO } \\
\text { R }\end{array}$ \\
\hline $\begin{array}{l}\text { Programa de Ecoformaçáo } \\
\text { Continuada de Docentes e } \\
\text { Gestores em Escolas Criativas de } \\
\text { Massaranduba }\end{array}$ & 2018 & $\begin{array}{l}\text { Membros RIEC } \\
\text { ECOFOR }\end{array}$ & $\begin{array}{l}\text { (Eco) } \\
\text { Formação } \\
\text { de } \\
\text { Professores } \\
\end{array}$ & $\begin{array}{l}\text { Secretaria de } \\
\text { Educaçáo de } \\
\text { Massarandub } \\
\text { a (SC) } \\
\end{array}$ & $\begin{array}{l}\text { RIEC } \\
\text { ECOFO } \\
\text { R }\end{array}$ \\
\hline $\begin{array}{l}\text { Ecoformaçáo e Sentipensar: } \\
\text { valorizando as inter-relaçóes }\end{array}$ & 2019 & $\begin{array}{l}\text { Membros RIEC } \\
\text { FURB e RIEC } \\
\text { ECOFOR }\end{array}$ & $\begin{array}{l}\text { (Eco) } \\
\text { Formaçáo } \\
\text { de } \\
\text { Professores }\end{array}$ & $\begin{array}{l}\text { Secretaria de } \\
\text { Educação de } \\
\text { Indaial (SC) }\end{array}$ & $\begin{array}{l}\text { RIEC } \\
\text { ECOFO } \\
\mathrm{R}\end{array}$ \\
\hline $\begin{array}{l}\text { Planejamento, Avaliaçáo, } \\
\text { Registro na Educaçáo Infantil }\end{array}$ & 2019 & $\begin{array}{l}\text { Membros RIEC } \\
\text { FURB e RIEC } \\
\text { ECOFOR }\end{array}$ & $\begin{array}{l}\text { (Eco) } \\
\text { Formaçáo } \\
\text { de } \\
\text { Professores } \\
\end{array}$ & $\begin{array}{l}\text { Secretaria de } \\
\text { Educação de } \\
\text { Ascurra (SC) }\end{array}$ & $\begin{array}{l}\text { RIEC } \\
\text { ECOFO } \\
\text { R }\end{array}$ \\
\hline $\begin{array}{l}\text { Programa de Ecoformaçáo } \\
\text { Continuada em Escolas } \\
\text { Criativas }\end{array}$ & 2019 & $\begin{array}{l}\text { Membros RIEC } \\
\text { FURB e RIEC } \\
\text { ECOFOR }\end{array}$ & $\begin{array}{l}\text { (Eco) } \\
\text { Formação } \\
\text { de } \\
\text { Professores } \\
\end{array}$ & $\begin{array}{l}\text { Secretaria de } \\
\text { Educação de } \\
\text { Gaspar (SC) }\end{array}$ & $\begin{array}{l}\text { RIEC } \\
\text { ECOFO } \\
\text { R }\end{array}$ \\
\hline $\begin{array}{l}\text { Certificaçáo de Docente } \\
\text { Ecoformadora Criativa }\end{array}$ & 2019 & $\begin{array}{l}\text { Vera Lúcia de Souza } \\
\text { e Silva, Vera Lúcia }\end{array}$ & $\begin{array}{l}\text { Certificaçá } \\
\text { o }\end{array}$ & $\begin{array}{l}\text { Barcelona } \\
\text { (ES) }\end{array}$ & $\begin{array}{l}\text { RIEC } \\
\text { ECOFO }\end{array}$ \\
\hline
\end{tabular}




\begin{tabular}{|l|l|l|l|l|l|}
\hline pela RIEC ADEC & & $\begin{array}{l}\text { Simáo, Marlene } \\
\text { Zwierewicz, Jeane } \\
\text { Pitz Pukall }\end{array}$ & & & $\begin{array}{l}\text { R e } \\
\text { RIEC } \\
\text { UNIAR } \\
\text { P }\end{array}$ \\
\hline $\begin{array}{l}\text { Certificaçáo de Instituiçáo } \\
\text { Criativa pela RIEC ADEC }\end{array}$ & 2019 & Instituto CRESCER & $\begin{array}{l}\text { Certificaçáa } \\
\text { o }\end{array}$ & $\begin{array}{l}\text { Barcelona } \\
\text { (ES) }\end{array}$ & $\begin{array}{l}\text { RIEC } \\
\text { ECOFO } \\
\text { R }\end{array}$ \\
\hline Pós-doutorado & 2020 & $\begin{array}{l}\text { Membros RIEC } \\
\text { FURB e RIEC } \\
\text { ECOFOR }\end{array}$ & $\begin{array}{l}\text { Pesquisas } \\
\text { em } \\
\text { andamento } \\
\text { lançamento } \\
\text { de Livro } \\
\text { (no prelo) e } \\
\text { publicaçáo } \\
\text { de Artigos }\end{array}$ & $\begin{array}{l}\text { Universidade } \\
\text { de Barcelona } \\
\text { (ES) }\end{array}$ & $\begin{array}{l}\text { RIEC } \\
\text { ECOFO } \\
\text { R }\end{array}$ \\
& & & & \\
& & & & \\
& & & \\
\hline
\end{tabular}

Fonte: dos autores (2020).

Como professores, somos parte de uma história que tem sido permeada pelo sentimento de insatisfação em relação aos processos de formação docente, derivado da existência de uma distância profunda entre as projeçóes teóricas e a realidade concreta. É como se houvesse um fosso inatingível entre a universidade e as escolas, e a elaboração acadêmica pouco contribuísse para transformar a condição socioprofissional dos docentes (NÓVOA, 2017), indicando a urgência de se repensar a formação docente para aproximá-la das demandas profissionais das instituiçóes de ensino e da sociedade, alinhando-a à valorização da dimensão universitária, intelectual e investigativa.

Na prática pedagógica, esse fosso é caracterizado por Morin (2010) ao afirmar que há uma inadequação cada vez mais ampla, profunda e grave entre os saberes compartimentados entre disciplinas, e, por outro lado, realidades ou problemas cada vez mais transversais, multidimensionais e transnacionais, globais, planetários.

Uma das mais importantes funçóes da escola é interagir e articular-se com práticas sociais, religando diferentes saberes relacionados a aspectos da realidade local e global, culturais, econômicos, políticos, em direção ao fortalecimento de uma justiça social.

Por isso, torna-se imprescindível explorar na escola - e na própria formação docente - temas como desenvolvimento, consciência e sustentabilidade. Esses temas podem compor um leque de possibilidades para projetos de ensino e aprendizagem norteados pelo pensamento complexo (MORIN, 2010), pela transdisciplinaridade (NICOLESCU, 1999). Esse é 
um dos propósitos da RIEC ECOFOR, aproximar os processos de formação docente às demandas e necessidades das escolas, criando vínculos entre propostas de formação e o contexto das escolas. Promove-se, assim, uma relação (auto)reflexiva entre a cultura da escola e os pressupostos da formação de professores ao interligar de forma indissociável teoria e prática nas vivências educativas. São açôes que fortalecem o implemento da justiça social no dia a dia da escola.

Em função da base epistemológica que norteia a RIEC, compreendemos que o ato de educar vai além do ensinar e aprender conteúdos curriculares, podendo ser uma maneira de se entender a realidade local e global, despertando para uma tomada de consciência sustentável e sistêmica. Mais que conhecimentos construídos, aprendidos, desaprendidos e reaprendidos, o ato educativo torna-se impulsionador de novas conexóes comprometidas com o bem-estar pessoal, social e ambiental.

Desde sua criação, foram várias as açóes desenvolvidas pelo Núcleo RIEC ECOFOR, entre as quais estão processos de formação de professores, pesquisas, eventos e publicaçóes. Uma dessas açóes, que merece destaque pela sua abrangência e alcance, é o Programa de (Eco)formação Continuada de Gestores e Docentes em Escolas Criativas na Rede Municipal de Ensino de Massaranduba (SC), cujas atividades foram iniciadas em 2018 com continuidade até a data de publicação deste artigo.

O citado Programa se propóe a alcançar o seguinte objetivo geral: promover açóes formativas e de planejamento que valorizem o potencial criativo de gestores e docentes da Rede Municipal de Ensino de Massaranduba (SC), por meio de estratégias que facilitem o acesso às bases teóricas norteadoras das Escolas Criativas, bem como o apoio à elaboraçáo, sistematização, desenvolvimento e difusão de iniciativas transformadoras, vinculadas a um ensino transdisciplinar e ecoformador e ao desenvolvimento de cidades sustentáveis e de justiça social.

Em um contexto de relaçóes complexas atua o Programa de (Eco)Formação Continuada, promovendo desde 2018 formação continuada para aproximadamente 200 profissionais da educação (120 da Educação Infantil e 80 do Ensino Fundamental), contando com a participação de gestores e docentes e profissionais-técnicos que atuam nas 12 instituiçôes de ensino vinculadas à Rede Municipal de Ensino de Massaranduba, das quais seis são de Educação Infantil e seis de Ensino Fundamental. 
Alguns aspectos diferenciais nos permitem anunciar como pertinentes do programa de formação continuada de Massaranduba, que também ocorrem em escolas das redes municipais de ensino de Gaspar e Indaial (SC). Um diferencial diz respeito ao cenário ecoformador, escolhido para dar início ao trabalhos. Cenários ecoformadores, são como espaços acessíveis, desenvolvidos de forma colaborativa que promovem "[...] a interação e o protagonismo na realização de vivências/experiências para valorização das relaçóes consigo mesmo, com o outro e com o meio natural e social [...]" (ZWIEREWICZ; SIMÃO; SILVA, 2019, p. 85, para sentir e pensar sentipensar, a partir da perspectiva da auto-hetero-ecoformação. Os resultados alcançados pelo programa, baseados nos pressupostos teórico-metodológicos do pensamento complexo, da transdisciplinaridade e da ecoformação, revelaram-se em diferenciais tais como o tempo e frequência dos encontros, tempo dedicado aos processos de auto e heteroformação, viagens de estudo para ampliar o repertório científico-cultural, partilha de saberes e espaços de formação mútua, realização de Projetos Criativos Ecoformadores (PCE), um projeto por unidade escolar, participação de toda a equipe de gestores e professores da formação, formação em serviço, inclusão de aspectos de pesquisa nos programas, relação com a comunidade local e com universidades, presença de um professor articulador por unidade escolar, fomento à participação em eventos científicos com publicaçóes dos resultados e alinhamento com a RIEC para busca de certificação como instituição criativa.

Iniciamos pela importância do tempo dedicado aos programas em diversas regiôes. Conforme a disponibilidade e vontade política da instituição ou rede de ensino, o tempo e frequência dos encontros nos "programas" se revelam como encontros mensais ou quinzenais, estendendo-se ao longo do ano; não se trata aqui de formaçóes isoladas, palestras ou apenas como encontros pontuais de poucas horas. O Programa abarca cargas horárias que variam de $80 \mathrm{~h}$ a $288 \mathrm{~h}$ em encontros anuais. Isso traz uma possibilidade de ampliação e de acompanhamento desses encontros, que acontecem presencialmente e a distância, criando uma "cultura" de formação continuada e em serviço, pois os acompanhamentos dos planejamentos e implementação dos projetos também acontecem dentro dos espaços escolares, onde as formadoras podem ter mais proximidade com estudantes, gestores e professores na prática docente cotidiana. Essa dinâmica de interação favorece 
os processos de mediação e aprofundamento das práticas pedagógicas nas rotinas das instituiçôes educacionais em formação.

Outro aspecto importante a se destacar é o tempo dedicado às práticas e momentos de auto e heteroformação durante o processo de ecoformação, que acaba sendo ampliado em um programa contínuo de formação como o apresentado aqui. Isso beneficia momentos de integração inter e intrapessoais. O que favorece uma maior coesão nos grupos e sentido de pertencimento ao coletivo da instituição, pois esses são os pontos fortes, intensificados durante os encontros.

São evidências do potencial polinizador da RIEC, assim como definido por Torre (2019, p. 32, tradução nossa), polinizar trata do:

Processo no qual o pólen se move de a parte masculina de uma flor (estames) para a parte feminina (pistilo) de uma flor da mesma espécie, que pode até ser a mesma flor da qual saiu o pólen. É a etapa anterior à fertilizaçáo de plantas com flores. $\mathrm{O}$ transporte do pólen é facilitado pela ação do vento, insetos, pássaros e outros animais.

Em decorrência desse processo, gera-se uma nova vida, um novo resultado, ou seja, a frutificação. Com o foco na polinizaçáo, Saturnino de la Torre relata que o conceito "polinização psicopedagógica" surgiu por intermédio de observaçóes da natureza, mais especificamente de um pé de laranjeira.

$\mathrm{Na}$ polinização, a espécie vegetal vive, vive e sobrevive propagando-a. Frutifica a flor para que uma nova fruta surja, compartilhe suas propriedades e dê continuidade às espécies. É exatamente isso que acontece com a criatividade. A criatividade traz algo novo, compartilha e sobrevive além do fato particular. Ao criar, a pessoa, grupo ou organizaçáo gera algo diferente e valioso, compartilha com os próximos e, ao fazê-lo, o trabalho sobrevive à pessoa ou grupo que o criou. Viver, viver e sobreviver, forma a tríade compartilhada por Polinização e Criatividade. (TORRE et al., 2019, p. 35-36, tradução nossa).

A partir de Torre et al. (2019), podemos identificar no processo de polinização os conceitos de explorar, compartilhar a transportação do pólen, conectar o masculino e o feminino, fertilizar e germinar a definir polinizaçáo psicopedagógica: 
Compartilhar: Ato de troca de informaçóes e conhecimentos, como o acontecimento da transferência do pólen de um lugar para o outro, deve-se apresentar como agentes de transferência e compartilhamento, estando constantemente atentos, compartilhando e espalhando nossos conhecimentos. Conectar: Se igualar ao estame e estigma, se conectando com o ambiente, com a proposta, com a ideia apresentada, criada e explorada, se permitindo ter uma ligação, uma conexão, pois sem isso o ato se torna infrutífero, incapaz de produzir conhecimentos e aprendizagens relevantes. Fecundar: Se entregar ao momento, se dedicar em buscas, em observaçóes e soluçóes, é o ato de germinar, de se tornar fértil, de estar apto a adquirir o conhecimento e a transmitilo. Frutificar: Dar semente, dar fruto, dar flor, é evoluir, se desenvolver e demonstrar o que foi aprendido, o resultado daquilo o qual se foi apresentado, dando origem a novas espécies, a novos saberes. (TORRE et al., 2019, p. 41-42, grifo e tradução nossas).

O Programa de (Eco)formação Continuada de Gestores e Docentes em Escolas Criativas, além de resgatar, reconhecer e difundir (polinizar) os processos criativos, atua na realidade educacional, social, global, transformando-a e requerendo uma cidadania planetária. $\mathrm{O}$ estudante desta sociedade globalizada, deve tornar-se sujeito para o sentipensar, a fim de buscar soluçóes ecoformadoras, sustentáveis, humanas frente ao caos, a incertezas proeminentes de uma sociedade em constante transformação. A escola é um espaço de promoção de justiça social e, para tanto, é também espaço para se consolidar açóes em direção de uma sociedade cada vez mais humana e da cultura de paz.

Pode-se entender que esse ato grandioso de reprodução das flores gera uma nova vida, um novo resultado, uma frutificação, denotando o potencial polinizador dos núcleos da RIEC FURB e RIEC ECOFOR.

\section{Consideraçóes finais}

Os resultados apontam para avanços em direção a processos e práticas pedagógicas mais alinhadas com os princípios das escolas criativas, que, conforme nos indica Torre (2013, p. 13),

são instituiçóes que vão mais adiante do lugar do qual partem (transcendem), que dão mais do que têm e ultrapassam o que delas se 
espera (recriam), que reconhecem o melhor de seus estudantes e professores (valorizam), que crescem por dentro e por fora, buscando em tudo a qualidade e a melhora (transformam).

A partir das evidências destacadas no Quadro1, que apresenta pesquisas e ações proeminentes dos Núcleos RIEC FURB e RIEC ECOFOR, observamos o alinhamento das açóes em relação aos objetivos da RIEC. No objetivo primeiro, criar uma consciência coletiva de mudança, promoveu-se por meio de instituiçóes, criativas e inovadoras, encontros e desenvolvimento de pesquisas oportunizando uma educação transformadora baseada em valores humanos e habilidades para a vida. A RIEC, ao ajudar a criar uma consciência coletiva, colabora para superar a cegueira do conhecimento por meio de suas diversas açóes, consolidando a justiça social.

No objetivo segundo, gerar açóes transformadoras, reconheceu-se e difundiu-se (polinizou-se) o potencial criativo de escolas e instituiçóes educativas com trajetórias inovadoras, como referência e inspiração a outras escolas e ao poder público para nortear a criação de políticas públicas. Ao resgatar, reconhecer e difundir açóes humanizadoras e criativas nos processos e avanços educativos, potencializam e polinizam açóes para justiça social.

Finalmente, no objetivo terceiro, promover açóes investigadoras e polinizadoras, investiu-se em pesquisas em âmbito de graduação e pósgraduação (Mestrado, Doutorado e Pós-Doutorado) a fim de desenvolver a criatividade, além de ensinar e aprender conteúdos curriculares, compreendendo e transformando a realidade das instituiçóes de ensino. Ao investir em pesquisas que venham a contribuir para a melhoria da qualidade da formação inicial e continuada de professores com vistas a uma educação transformadora, ecoformadora, sustentável, planetária, democrática são possibilidades com o objetivo de promover a justiça social.

O potencial polinizador para justiça social demonstrou que as açóes iniciadas no Núcleo RIEC FURB reverberaram na consolidação e oficialização de açóes no Núcleo RIEC ECOFOR. Assim, do mesmo modo que uma flor que não poliniza, isto é, cai antes da formação do fruto, ideias que não se comunicam, não são contrastadas ou valorizadas, não desenvolvem e nem produzem frutos (TORRE, 2003). Quando o trabalho é feito de forma conjunta, em que os envolvidos trabalham pela obra e pelo bem comum, ao 
final, todos serão contemplados com um jardim repleto de flores e frutos. Assim é a RIEC.

\section{Referências}

MORIN, Edgar. A cabeça bem-feita: repensar a reforma, reformar o pensamento. 18. ed. Rio de Janeiro: Bertrand Brasil, 2010.

MORIN, Edgar. Os sete saberes necessários à educação do futuro. São Paulo: Cortez; 2011.

NICOLESCU, Basarab. O manifesto da transdisciplinaridade. 2. ed. São Paulo: Triom, 1999.

NÓVOA, António. Firmar a posição como professor, afirmar a profissão docente. Cadernos de Pesquisa, [s. l.], v. 47, n. 166, p. 1106-1133, out./dez. 2017. Disponível em: http://www.scielo.br/pdf/cp/v47n166/1980-5314-cp47-166-1106.pdf. Acesso em: 23. Set. 2020

RIEC. Red Internacional de Escuelas Creativas. Acta de prioridades y reorganización de RIEC. Palmas: RIEC, 2017.

SILVA, Vera Lúcia de Souza e; TORRE, Saturnino de la. Ecoformação e transdisciplinaridade na rede de escolas criativas. In: SCHROEDER, Edson; SILVA, Vera Lúcia de Souza e (org.). Novos talentos: processos educativos em ecoformação. Blumenau: Legere, 2014. p. 29-43.

TORRE, Saturnino de la. Carta da Fundação RIEC ECOFOR. Barcelona: RIEC ECOFOR, 2018.

TORRE, Saturnino de la. Dialogando con la creatividad. Barcelona: Octaedro, 2003.

TORRE, Saturnino de la. Escolas criativas: escolas que aprendem, criam e inovam. In: ZWIEREWICZ, Marlene; TORRE, Saturnino de la (org.). Uma escola para o século XXI: escolas criativas e resiliência na educação. Florianópolis: Insular, 2009. p. 55-69.

TORRE, Saturnino de la. Instituciones educativas creativas - Instrumento para valorar el desarrollo creativo de las instituciones educativas (VADECRIE). Sitges (Espanha): Círculo Rojo, 2012. 
TORRE, Saturnino de la. Movimento de escolas criativas: fazendo parte da história de formação e transformação. In: ZWIEREWICZ, Marlene (org.). Criatividade e inovação no ensino superior: experiências latino-americanas e europeias em foco. Blumenau: Nova Letra, 2013. p. 139-162.

TORRE, Saturnino de la; ZWIEREWICZ, Marlene; SIMÃO, Vera Lúcia; SILVA, Vera Lúcia de Souza e. Ecoformação de professores com polinização de escolas criativas. Caçador: UNIARP, 2019.

ZWIEREWICZ, Marlene; SIMÁO, Vera Lúcia; SILVA, Vera Lúcia de Souza e. Da formação docente ao protagonismo infantil na criação de cenários ecoformadores. Revista Electrónica de Investigación y Docencia (REID), [s. l.], n. especial, p. 83-94, out, 2019. DOI: 10.17561/reid.m4.6.

Recebido em: 13 ago. 2020

Aceito em: 03 set. 2020 